Correspondence

\title{
Physical incompatibility between Furosemide and Rocuronium Bromide
}

\section{Barkha Bindu, Surya K. Dube, Girija P. Rath}

Rocuronium bromide is a commonly used neuromuscular blocking agent in the present day neuroanaesthetic practice. Furosemide is a diuretic agent used in

neurosurgical patients to reduce the intracellular and extracellular fluid compartments of the brain. ${ }^{[1]} \mathrm{We}$ report an observation of a physical incompatibility between these two commonly used agents.

A 59-year-old, 69-kg male was posted for elective craniotomy and resection of temporal meningioma. Preoperative treatment history of the patient revealed intake of phenytoin $100 \mathrm{mg}$ orally twice daily since last 7 months. During the surgical procedure, a 14G intravenous (IV) cannula was secured in the left forearm and $0.9 \%$ saline was administered via a $50 \mathrm{~cm}$ long extension line. As the patients receiving chronic anticonvulsant medications are resistant to non-depolarizing muscle relaxants, ${ }^{[2]}$

Department of Neuroanesthesiology, All India Institute of Medical Sciences, New Delhi, India

Address for correspondence:

Dr. Girija Prasad Rath, Department of Neuroanesthesiology, Neurosciences Center, All India Institute of Medical Sciences,

New Delhi - 110 029, India. E-mail: girijarath@yahoo.co.in 
it was decided to maintain intraoperative muscle relaxation through infusion of rocuronium bromide at the rate of $10 \mu \mathrm{g} / \mathrm{kg} / \mathrm{min}$ through the extension line. Intraoperatively, furosemide $10 \mathrm{mg} I V$ was administered through the extension line. Immediately after injection of furosemide, a white precipitate was observed inside the tubing of the extension line. The infusion was stopped and the extension line was replaced. A new IV access was established and furosemide was administered.

Rocuronium bromide is supplied as an isotonic solution $(10 \mathrm{mg} / \mathrm{ml})$ for IV use and each millilitre of the drug contains $2 \mathrm{mg}$ sodium acetate and $3.3 \mathrm{mg}$ sodium chloride. The aqueous solution is adjusted to a $\mathrm{pH}$ of 4 with acetic acid and/or sodium hydroxide. Furosemide injection $(10 \mathrm{mg} / \mathrm{ml})$ contains sodium chloride, sodium hydroxide and, if necessary, hydrochloric acid to adjust $\mathrm{pH}$ between 8.0 and 9.3. In this case, it seems the acidic nature of rocuronium bromide and the alkaline nature of furosemide was responsible for the formation of precipitates when the two agents were mixed.

Incompatibility of methyl prednisolone succinate and vecuronium bromide has been reported previously and the possibility of pulmonary embolism with particle size more than $6 \mu \mathrm{m}$ has been cautioned. ${ }^{[3]}$ However, it is not known whether the particle size of the precipitate formed by furosemide and rocuronium admixture results in a similar size to cause pulmonary embolism.
Both rocuronium and furosemide are commonly used during in neurosurgical procedures; and we would like to re-emphasise the incompatibility of the two agents which despite a known fact, is often forgotten in the operation room. Hence, we suggest routine use of these two agents through different IV access whenever a co-administration is planned.

\section{REFERENCES}

1. Cottrell JE, Robustelli A, Post K, Turndorf H. Furosemide and mannitol induced changes in the intracranial pressure and serum osmolality and electrolytes. Anesthesiology 1977;47:28-30.

2. Naguib M, Lien CA. Pharmacology of muscle relaxants and their antagonists. In: Miller RD, editor. Miller's Anesthesia. $7^{\text {th }}$ ed. Vol 1 Philadelphia: Churchill Livingstone, Elsevier. 2010. p. 559-70.

3. Prabhakar H, Ali Z, Rath GP, Sheikh IA. Vecuronium bromide and methyl prednisolone succinate are physically incompatible!. J Neurosurg Anesthesiol 2008;20:153-4.

\begin{tabular}{|l|l|}
\hline \multicolumn{2}{|c|}{ Access this article online } \\
\hline Quick Response Code: & Website: \\
\hline & www.jnaccjournal.org \\
\cline { 2 - 2 } & \\
\hline
\end{tabular}

